\title{
Viscoelastic Characterization of Pasta Dough Supplemented of Cassava Bagasse and Hydrocolloids
}

\author{
C. Acosta Andrea*, J. Hernandez Elvis and M. Salcedo Jairo \\ Department of Agro industrial Engineering, Universidad de Sucre, Kra.28 \# 5-267, Sincelejo, Sucre, Colombia; an- \\ dreina9110@hotmail.com,elvi.hernandez@unisucre.edu.co, jairo.salcedo@unisucre.edu.co
}

\begin{abstract}
Objective: To develop fiber-rich pasta by partially replacing wheat semolina with cassava bagasse and incorporation Carboxymethylcellulose (CMC). Methods/Analysis: Pasta was made with cassava bran (10, 20 and 30\% w/w) and carboxymethylcellulose - CMC $(0.5,1$ and $1.5 \% \mathrm{w} / \mathrm{w})$. A rheological characterization of the products was carried out. The pasta that presented the best rheological characteristics was subjected to a sensory analysis to determine its degree of acceptance. Findings: Partial replacement of wheat semolina by cassava bagasse and the addition of Carboxymethylcellulose showed predominance of storage modulus over loss modulus in dynamic oscillatory tests and, In addition, by increasing the bagasse content of cassava and hydrocolloid a predisposition of increase in the modules was observed, probably associated with the effect fiber has on water absorption, generating a more solid dough and the ability of this hydrocolloid to mimic viscoelastic properties of gluten. Sensory characterization of pasta decreased with the increase in cassava bagasse content, however, adding the hydrocolloid improved its quality. Novelty: Incorporation of cassava bagasse in pasta is an alternative to improve its nutritional composition by increasing its fiber content.
\end{abstract}

Keywords: Fiber, Hydrocolloid, Sensory, Viscoelasticity

\section{Introduction}

Cassava is a plant of integral use since its roots and leaves are source of carbohydrates and proteins; roots are used for human diet as fresh food, croquettes, flour and starch; in animal feed it is used as a supplement in concentrates for poultry, pigs and ruminants; and at industrial level in obtaining starch, flour, alcohol fuel, gum, adhesives, dextrin, glucose, among others ${ }^{1}$.

In the process of obtaining cassava starch, waste harmful to the environment is generated, mainly husk, wastewater, and cassava bagasse ${ }^{2}$. Its incorrect disposal represents a loss for starch industry, due to its composition and large quantities produced. Cassava bagasse, is the waste generated in greater amounts, $1507 \mathrm{~kg}$ of cassava bagasse are produced per ton of processed cassava in wet basis. As for its chemical composition, dry cassava bagasse has $15 \%$ to $20 \%$ moisture content; $60 \%$ to $70 \%$ correspond to starch, and $12 \%$ to $14 \%$ to fiber ${ }^{3}$. However, fiber content may vary depending on the variety of cassava and technology used in starch extraction, resulting in higher or lower fiber values ${ }^{4}$.

The addition of fiber of origin vegetable to products constitutes an alternative for the to obtain advantage of agro-industrial co-products such as cassava bagasse, which, thanks to its dietary fiber content, can give added value to food products 5 . Studies to incorporate raw materials of local origin in popular foods such as bread, pasta, among others have been reported. Pasta has a low glycemic index ${ }^{6}$, which is beneficial for the health of diabetic people, it also has a high energy value, and other benefits that make it a very popular food among consumers and 
commonly used for the addition of nutrients. When of foods are added with fiber, sensory attributes and cooking properties can be affected in an undesirable way. Producing these enriched foods is a challenge between improving their nutritional value and preserving the organoleptic properties desired by the consumer?

In order to preserve the quality of enriched products, hydrocolloids are used due to their properties as gelling agents, emulsifiers, and fat substitutes, stabilizers to provide viscosity, improve firmness and give body to the final product, besides being useful to improve food sensory characteristics by modifying rheological properties ${ }^{8,9}$. Hydrocolloids in baking favor the machinability of dough, retain moisture and improve appearance; they are generally used in gluten-free formulations, being essential ingredients to obtain a structure similar to that provided by gluten ${ }^{10}$. Gluten network gives dough a unique functionality, which rheological behavior as a viscoelastic fluid makes it more extensible and elastic ${ }^{11}$.

The addition of hydrocolloids with high water binding capacity to pasta helps control dough rheology, texture characteristics, and decreases cooking loss ${ }^{12}$.

The objective of this study was to develop fiber-rich pasta by partially replacing wheat semolina with cassava bagasse and incorporation Carboxymethylcellulose (CMC) as structuring agent, obtaining a functional food to consumers.

\section{Materials and Methods}

\subsection{Materials}

Materials used to make the dough were; wheat semolina, Carboxymethylcellulose (CMC) and cassava bagasse obtained during the obtaining process of native starch.

Cassava bagasse was previously conditioned before being used in the preparation of pasta. A 10PSI press was made to decrease water content, followed by a drying process until a humidity of $11 \%$. To finish with the process the grinding and sieving process to obtain uniformity in the final product ${ }^{4}$.

Pasta was prepared according to the following elaboration process: mixing ingredients; wheat semolina, cassava bagasse and salt ( $1 \%$ flour-based) for $5 \mathrm{~min}$; dissolution of CMC in water until achieving a uniform distribution ${ }^{8}$, mixing and kneading ingredients in the fettuccine type pasta extruder machine, and drying until a final moisture between 10 and $11.5 \%$.

\subsection{Methods}

\subsubsection{Viscoelastic Properties of Dough}

Viscoelastic properties of each sample were analyzed using a Modular Compact Rheometer MCR 302, connected to the Anton PaarRheoCompass1.12 software. Parallel-plate geometry with diameter of $25 \mathrm{~mm}$ with a separation of $1 \mathrm{~mm}$ was used. The sample was placed in the equipment leaving it to rest for 15 minutes. Linear viscoelastic region (LVR) was determined by performing an amplitude sweep in a range of deformation between $0.01-100 \%$ and frequency of $1.0 \mathrm{~Hz}$. Frequency sweep test was performed varying the frequency of $0.01-10 \mathrm{~Hz}$ to determine storage modulus ( $G$ ') (elastic property) and loss modulus (G”) (viscous property). Data were adjusted to power law model (Equation 1 and 2. Then, tang delta $\tan ()$ was determined (Ec. 3) ${ }^{8}$.

$$
\begin{aligned}
& G^{\prime}=K^{\prime}(\omega)^{n^{\prime}} \\
& G^{\prime \prime}=K^{\prime \prime}(\omega)^{n^{\prime \prime}} \\
& \tan (\delta)=\frac{\mathrm{G}^{\prime \prime}}{\mathrm{G}^{\prime}}
\end{aligned}
$$

\section{Sensory Analysis}

Sensory Analysis was performed using an acceptance test with a mixed structured 9-point hedonic scale. Texture (firmness and elasticity), color, taste and overall acceptability attributes of the product were evaluated, with help of a panel of 50 habitual consumers of pasta tasters. Finally, the most accepted pasta was selected for its subsequent sensory evaluation versus a traditional commercial fetuccini.

Pasta was previously hydrated in hot water taking into account the ratio one liter of water per $100 \mathrm{~g}$ of pasta during the optimal cooking time, that is, total cooking to the interior of pasta. Samples were drained from boiling water and immersed immediately in water at a temperature of approximately $25^{\circ} \mathrm{C}$. Then they were placed under heat conditions before being served to tasters without addition additives ${ }^{13}$. The experimental design for sensory analysis was carried out by a completely random block design (DBCA), where tasters constitute the blocking factor. ANOVA at 5\% significance and Tukey test was applied to the results. 


\section{Bromatological Characterization}

It was made according to official AOAC standards, $2012^{14}$ for moisture content, ash, protein, carbohydrates, total fiber and fat. This characterization was made for pasta presenting a higher sensory evaluation.

\section{Statistical Analysis}

Data obtained were analyzed by a completely randomized design (DCA) with two factors: of incorporation of cassava bagasse $(10,20$ and $30 \%)$, and inclution of Carboxymethylcellulose (CMC) (0.5, 1, and 1.5\%), using R 3.2.1 software. An analysis of variance (ANOVA) was performed at a level of significance of $5 \%$ and Tukey test for comparison of means.

\section{Results and Discussion}

\subsection{Dough Rheology}

Results of dynamic rheological tests are shown through the modulus of elastic (G') and viscous modulus (G') as a function of the oscillation frequency, as evidenced in Figure 1. It is notable that the elastic modulus ( $\left.G^{\prime}\right)$ was greater than the viscous module ( $G$ ") over the entire frequency range studied, showing that elastic properties dominated over viscose properties, defining dough as an consistent elastic gel ${ }^{9}$. This behavior is typical in products containing gluten, which contributes to the creation of networks in the matrix and to the good consistency of the mass. A similar behavior was observed in gluten-free pasta $^{15}$, bread made with microalgae ${ }^{16}$, pastas added with dried blackcurrant pulp ${ }^{17}$ and pastas added with cassava bagasse and xanthan gum ${ }^{18}$, finding a predominant elastic behavior.

The increase in the content of cassava bagasse caused an upward predisposition in the value of the modules, corresponding to the increase in viscoelastic constants, which shows a stronger structure ${ }^{19}$. This can be attributed to the use of raw ingredients with high fiber content, with high fiber content on water absorption ${ }^{16}$. This ability is determined mainly by the presence of a large number of hydroxyl groups in fiber structure which interact with water through hydrogen bonds $s^{20}$, and therefore increase dough rigidity or act as filler in the viscoelastic matrix ${ }^{17}$. In addition, it was observed that the increase in CMC content increased both modules, which may be related to (a)

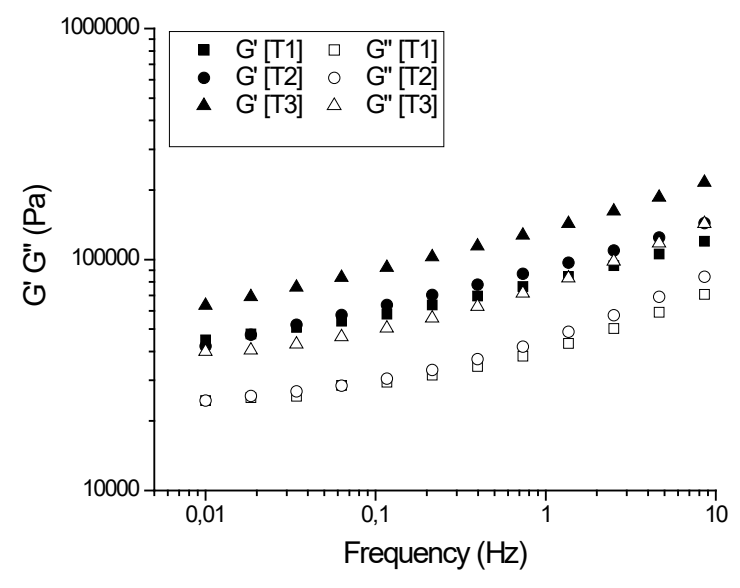

(b)

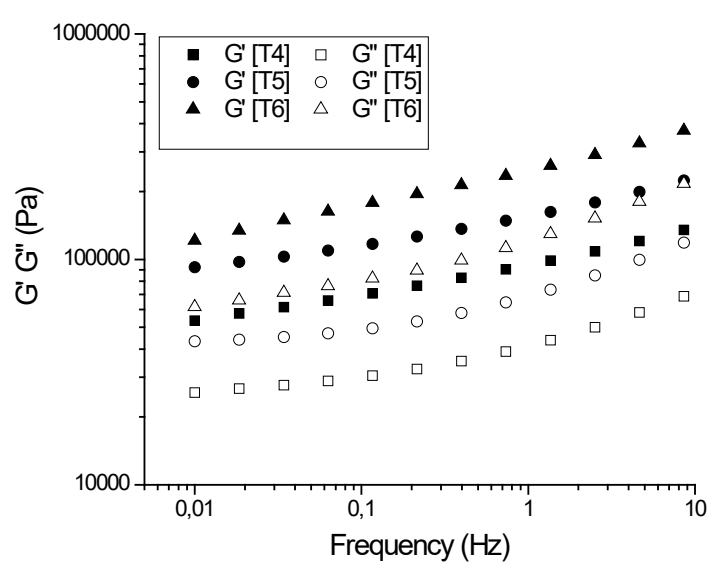

(c)

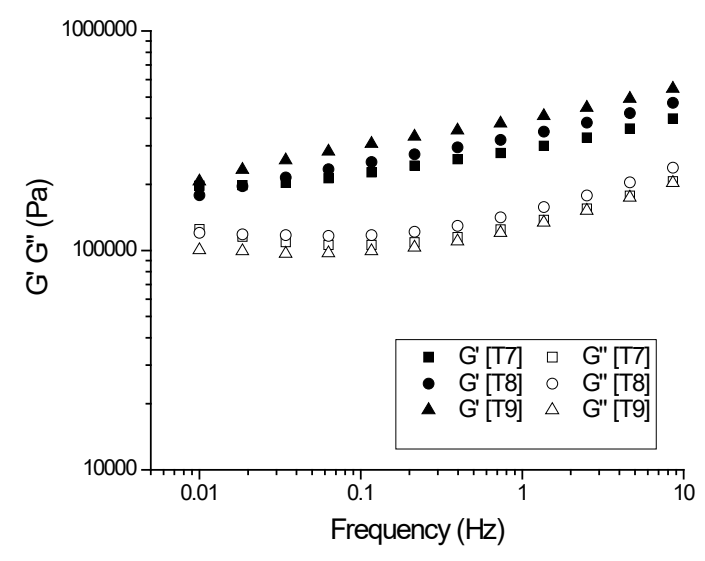

Figure 1. Viscoelastic behavior of dough for pasta with cassava bagasse in inclusions of (a) $10 \%$, (b) $20 \%$ and (c) $30 \%$ and supplemented with Carboxymethylcellulose $(\mathrm{CMC})$ in concentrations of: $(\mathbf{\square}, \square) 0.5 \%,(\bullet, \circ) 1 \%$ and $(\boldsymbol{\Lambda}, \Delta)$ 1.5\%. (Full symbols (G'); open symbols (G”). 
the ability of hydrocolloids to copy viscoelastic properties of gluten found in semolina ${ }^{21}$. There is a three-dimensional network in dough where carbohydrate molecules and proteins that trap starch granules interact; there, hydrocolloids like CMC have the ability to help form a cohesive network. Similar results were reported in gluten-free pasta added with xanthan gum and locust gum ${ }^{15}$, and in rice flour dough added with xanthan gum, obtaining stronger gels thanks to the thickener capacity of this hydrocolloid ${ }^{19}$.

Tables 1 and 2 show viscoelastic parameters (K', n', K' and $n$ "). It is observed that an increase in the amount of cassava bagasse causes higher values for K' and $\mathrm{K}^{\prime \prime}$ in all
CMC concentrations evaluated. This behavior is possibly due to the strengthening of dough structure thanks to the reinforcement of viscoelastic proteins network with particles of the new raw material evenly distributed within the gluten matrix. Similar results were reported by ${ }^{16}$ in dough added with microalgae up to a concentration of $3 \%$ and by ${ }^{17}$ in dough added with dried blackcurrant pulp.

An increase in $K^{\prime}$ and $K^{\prime \prime}$ values was found by increasing the CMC content in the dough formulation. This behavior can be due to the stabilizing and thickener properties of hydrocolloids. Research suggests that hydrocolloids interfere in the formation of gluten bonds, affecting both moduli differently, highlighting that gluten proteins

Table 1. Rheological parameters K' and K" of dough with cassava bagasse and added with CMC

\begin{tabular}{|c|c|c|c|}
\hline & Cassava bagasse (\%) & & \\
\hline \multirow{2}{*}{ CMC (\%) } & 10 & 20 & 30 \\
\hline & \multicolumn{3}{|l|}{$K^{\prime}$} \\
\hline 0,5 & $81653,2 \pm 6402,2^{\mathrm{bB}}$ & $95817,8 \pm 9801,9^{\mathrm{cB}}$ & $294805,0 \pm 6932,9^{\mathrm{cA}}$ \\
\hline 1 & $93218,1 \pm 4887,1^{\mathrm{bC}}$ & $158225,9 \pm 7967,4^{\text {bв }}$ & $338856,6 \pm 2995,1^{\mathrm{bA}}$ \\
\hline \multirow[t]{2}{*}{1,5} & $137243,1 \pm 8091,7^{\mathrm{aC}}$ & $251778,9 \pm 23928,6^{a \mathrm{~B}}$ & $449126,2 \pm 19934,2^{\mathrm{aA}}$ \\
\hline & \multicolumn{3}{|l|}{ K” } \\
\hline 0,5 & $42429,0 \pm 1277,6^{\mathrm{bB}}$ & $42943,5 \pm 2886,3^{\mathrm{cB}}$ & $137447,0 \pm 10589,1^{\mathrm{bA}}$ \\
\hline 1 & $46859,1 \pm 3218,5^{\mathrm{bC}}$ & $71509,7 \pm 5044,1^{\mathrm{bB}}$ & $155968,4 \pm 4637,9^{\mathrm{aA}}$ \\
\hline 1,5 & $79447,1 \pm 3756,1^{\mathrm{aB}}$ & $124759,2 \pm 14253,1^{\mathrm{aA}}$ & $132627,4 \pm 22536,7^{\mathrm{bA}}$ \\
\hline
\end{tabular}

Means with different letters in columns (lowercase) and rows (uppercase) indicate a statistically significant difference according to Tukey test $(\mathrm{p}<0.05)$.

Table 2. Rheological parameters n' and n" of dough with cassava bagasse and added with CMC

\begin{tabular}{|l|l|l|l|}
\hline \multirow{2}{*}{ CMC (\%) } & \multicolumn{2}{l|}{ Cassava bagasse(\%) } & \multicolumn{2}{l|}{$\mathbf{3 0}$} \\
\hline $\mathbf{0 , 5}$ & $\mathbf{1 0}$ & $\mathbf{2 0}$ & $0,143 \pm 0,002^{\mathrm{aC}}$ \\
\cline { 2 - 4 } & $\mathbf{n}$ & \multicolumn{2}{|l|}{} \\
\hline $\mathbf{1}$ & $0,180 \pm 0,00^{\mathrm{bA}}$ & $0,160 \pm 0,00^{\mathrm{bB}}$ & $0,154 \pm 0,006^{\mathrm{aB}}$ \\
\hline $\mathbf{1 , 5}$ & $0,203 \pm 0,003^{\mathrm{aA}}$ & $0,163 \pm 0,00^{\mathrm{bB}}$ & $0,111 \pm 0,032^{\mathrm{bC}}$ \\
\hline $\mathbf{0 , 5}$ & $0,212 \pm 0,002^{\mathrm{aA}}$ & $0,185 \pm 0,00^{\mathrm{aB}}$ & $0,193 \pm 0,003^{\mathrm{aC}}$ \\
\hline $\mathbf{1}$ & $\mathbf{n}$ & & $0,197 \pm 0,005^{\mathrm{aC}}$ \\
\hline $\mathbf{1 , 5}$ & $0,24 \pm 0,007^{\mathrm{bA}}$ & $0,221 \pm 0,006^{\mathrm{cB}}$ & $0,20 \pm 0,002^{\mathrm{aC}}$ \\
\hline
\end{tabular}

Means with different letters in columns (lowercase) and rows (uppercase) indicate a statistically significant difference according to Tukey test $(\mathrm{p}<0.05)$. 
(glutenins) have been associated with elastic behavior, and gliadins with viscous behavior ${ }^{22,23}$. Similar results were found in gluten-free dough added with hydrocolloids ${ }^{24}$.

The values obtained for n' and n" were different from zero, so can define dough rheological behavior as weak gels. Similar results were reported by ${ }^{17}$ in dough added with dried blackcurrant pulp. The highest values for n' and $n$ " were observed at the highest concentration of $\mathrm{CMC}$, observing the effect of the hydrocolloid used in dough only after $1.5 \%$. A similar behavior was reported in dough made with rice, observing that the incorporation of b-glucan did not show results at low concentrations ${ }^{25}$.

The behavior of Tan $(\delta)$ of the dough as a function of frequency is evidence in Figure 2. Tan $(\delta)$ reveals of the solid-liquid balance of a viscoelastic material; $0^{\circ}$ represents an ideal elastic solid and $90^{\circ}$ an ideal viscous liquid. Therefore, for values of $\operatorname{Tan}(\delta)<1\left(G^{\prime \prime}<G^{\prime}\right)$ a behavior similar to the solid is observed, while $\operatorname{Tan}(\delta)>1\left(G^{\prime \prime}>G^{\prime}\right)$ a behavior similar to the liquid is observed ${ }^{26}$. In the present study values for $\operatorname{Tan}(\delta)$ less than 1 was obtained, evidencing the behavior of dough as a viscoelastic gel, mainly similar to the solid. This may be due to semolina proteins linked together by disulfide bonds, hydrogen and hydrophobic bonds to create a matrix ${ }^{27}$. Similar behavior was found in dough made with different varieties of wheat ${ }^{28}$. Likewise, it was found the values of $\operatorname{Tan}(\delta)$ decrease at low frequencies $(<1.0 \mathrm{~Hz})$ and then increase, which indicates mobility within the gluten network chain.

Table 3 shows results of Tan $(\delta)$ less than 1 . Taking into account that low values of Tan $(\delta)$, indicate a structure in the most elastic dough ${ }^{28}$. In dough made with $10 \%$ cassava bagasse the highest values were found for $\operatorname{Tan}(\delta)$. This behavior coincides with values found in modules for dough prepared with the lowest content of cassava bagasse $(10 \%)$, where a minor loss of integrity of gluten network is presented, so its structure is affected to a lesser extent by the presence of fiber. Gluten network loss of structure is due to the dilution of wheat gluten by proteins and fiber of raw material used to replace semolina ${ }^{16}$. This type of substitution by fibrous materials generates changes on dough rheology ${ }^{29}$.

When using $\mathrm{CMC}$ at the highest concentration studied, the highest values were found for $\operatorname{Tan}(\delta)$, which favors the increase in gel strength, caused probably because the hydrocolloids improve the ratio between starch granules ${ }^{19}$. The type and amount of hydrocolloid added in the formulation to dough generates changes (a)

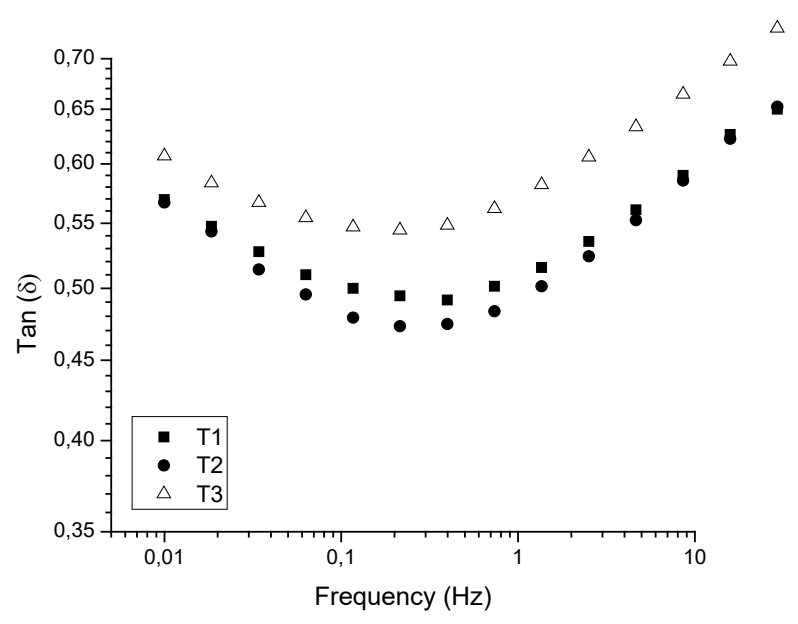

(b)

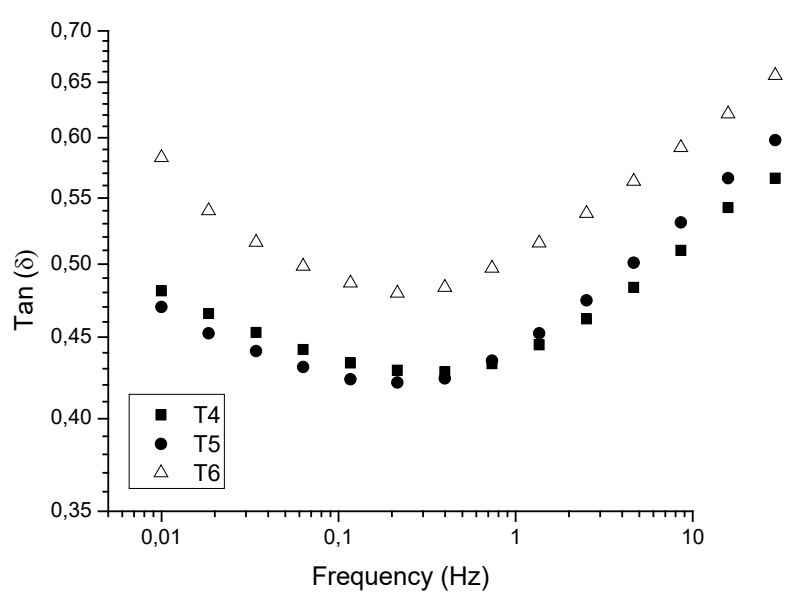

(c)

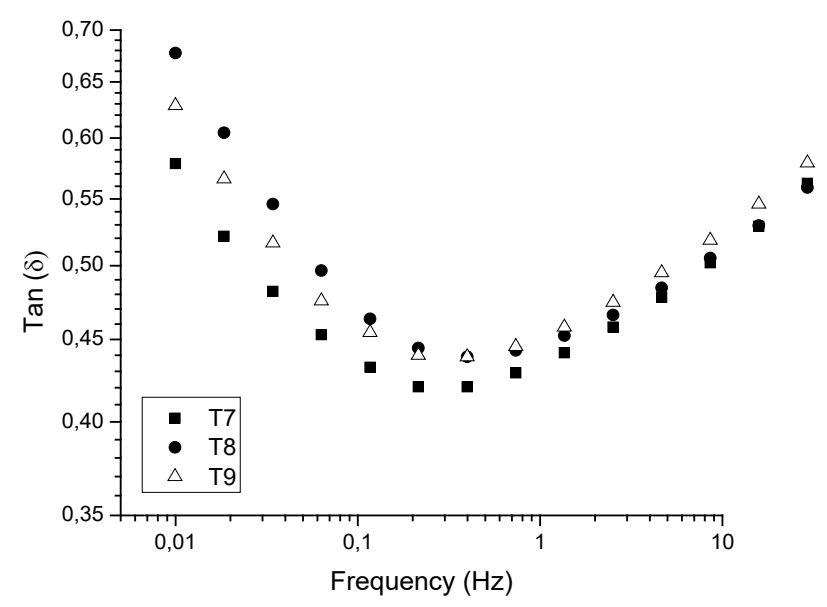

Figure 2. Behavior of Tan $(\delta)$ of dough with cassava bagasse in inclusions of (a) 10\%, (b) $20 \%$ and (c) $30 \%$ and added with Carboxymethylcellulose (CMC) in concentrations of $0.5 \%, 1 \%$ and $1.5 \%$. 
Table 3. Tan $(\delta)$ of dough with cassava bagasse and added with CMC

\begin{tabular}{|l|l|l|l|}
\hline & \multicolumn{3}{|l|}{ Cassava bagasse(\%) } \\
\hline CMC (\%) & $\mathbf{1 0}$ & $\mathbf{2 0}$ & $\mathbf{3 0}$ \\
\hline 0,5 & $0,5 \pm 0,026^{\mathrm{bA}}$ & $0,434 \pm 0,019^{\mathrm{bB}}$ & $0,433 \pm 0,002^{\mathrm{aB}}$ \\
\hline 1 & $0,479 \pm 0,005^{\mathrm{bA}}$ & $0,424 \pm 0,021^{\mathrm{bB}}$ & $0,464 \pm 0,014^{\mathrm{aA}}$ \\
\hline 1,5 & $0,547 \pm 0,01^{\mathrm{aA}}$ & $0,487 \pm 0,038^{\mathrm{aB}}$ & $0,455 \pm 0,004^{\mathrm{aB}}$ \\
\hline
\end{tabular}

Means with different letters in columns (lowercase) and rows (uppercase) indicate a statistically significant difference according to Tukey test $(\mathrm{p}<0.05)$.

on Tan $(\delta)$, which is related with molecular structure and conformation of the polysaccharide chain ${ }^{30}$. Dough rheological behavior is affected by the network structure of the hydrocolloids and gluten proteins, caused by their competition for water and intermolecular interactions. Hydrocolloids have strong ability to form complexes with gluten proteins through both ionic and non-ionic interactions, affecting dough strength ${ }^{23}$.

\section{Sensory Evaluation}

Table 4 shows results obtained for the acceptance of pasta, where it is evident that pasta made with $10 \%$ cassava bagasse and 0.5\% CMC obtained the highest acceptance in the almost attributes evaluated.

The evaluated attributes of texture, firmness, and elasticity were qualified by the tasters as: firmness between hedonic terms "I dislike slightly" and "I like moderately", and elasticity between "I dislike slightly" and "I like it slightly". Studies carried out by Mora, $2012^{31}$ found that the addition of CMC favored sensory attributes of texture in pasta added with quinoa.

For attributes of color, pasta made with $10 \%$ cassava bagasse and 1.5\% CMC obtained the highest averages, being rated by consumers in the hedonic term "I like moderately". This is possibly due to the fact that there is lesscassava bagasse that affects characteristic yellow color and also to the presence of CMC which favored coloration.

On the other hand, attributes of flavor and general sensation of pasta were cataloged by consumers between hedonic terms "I dislike slightly" and "I like slightly". Similar results in terms of overall acceptability were reported by ${ }^{13}$, obtaining scores of more than 6 when the addition of legume flours did not exceed $30 \%$.

To complement the sensory analysis in Table 5, the results of a comparison between the prepared paste with $10 \%$ cassava bagasse and $0.5 \%$ CMC versus a paste sold on the market are shown. Finding that the latter is located in the hedonic term "I like slightly". However, tasters did not find significant differences $(\mathrm{p} \geq 0.05)$ between samples regarding color attribute, although the addition of cassava bagasse generates browning in pasta, which is more noticeable in those made with $30 \%$ cassava bagasse.

Lower elasticity found in pasta containing cassava bagasse compared with the commercial one is possibly related to difficulty in creating the gluten network in the dough due to the fiber ${ }^{32}$.

Regarding the flavor attribute of pasta, it was observed that tasters preferred the commercial one. Similar results were reported by ${ }^{33}$ for pasta including lyophilized tomato.

Regarding the overall acceptability attribute significant differences were found, obtaining commercial pasta

Table 4. Results of pasta sensory analysis

\begin{tabular}{|c|c|c|c|c|c|c|}
\hline $\begin{array}{l}\text { Amount of } \\
\text { bran (\%) }\end{array}$ & $\begin{array}{l}\text { Amount of } \\
\text { CMC (\%) }\end{array}$ & Firmness & Elasticity & Color & Flavor & $\begin{array}{l}\text { General } \\
\text { Sensation }\end{array}$ \\
\hline \multirow{3}{*}{10} & 0,5 & $6,82 \mathrm{a}$ & $6,16 \mathrm{a}$ & $5,48 \mathrm{bc}$ & $5,28 \mathrm{a}$ & $6,00 \mathrm{a}$ \\
\hline & 1 & $4,78 \mathrm{c}$ & $4,90 \mathrm{bc}$ & $4,30 \mathrm{de}$ & $4,34 \mathrm{bc}$ & $5,04 \mathrm{bcd}$ \\
\hline & 1,5 & $4,60 \mathrm{c}$ & $5,30 \mathrm{ab}$ & $6,56 a$ & $5,36 \mathrm{a}$ & $6,32 \mathrm{a}$ \\
\hline \multirow{3}{*}{20} & 0,5 & $4,82 \mathrm{c}$ & $5,24 \mathrm{~b}$ & $5,90 \mathrm{ab}$ & $5,28 \mathrm{a}$ & $6,16 a$ \\
\hline & 1 & $5,04 \mathrm{bc}$ & $5,16 \mathrm{~b}$ & $5,28 \mathrm{bc}$ & $5,54 \mathrm{a}$ & $5,70 \mathrm{ab}$ \\
\hline & 1,5 & $4,72 \mathrm{c}$ & $5,24 \mathrm{~b}$ & $4,84 \mathrm{~cd}$ & $5,18 \mathrm{ab}$ & $5,12 \mathrm{bc}$ \\
\hline \multirow{3}{*}{30} & 0,5 & $4,62 \mathrm{c}$ & $4,16 c$ & $4,14 \mathrm{de}$ & $3,92 \mathrm{c}$ & $4,14 \mathrm{e}$ \\
\hline & 1 & $4,72 \mathrm{c}$ & $4,82 \mathrm{bc}$ & $3,90 \mathrm{e}$ & $3,78 \mathrm{c}$ & $4,26 \mathrm{de}$ \\
\hline & 1,5 & $5,68 \mathrm{~b}$ & $5,52 \mathrm{ab}$ & $3,44 \mathrm{e}$ & $4,96 \mathrm{ab}$ & $4,72 \mathrm{cde}$ \\
\hline
\end{tabular}

Means with different letters in columns indicate significant differences $(\mathrm{p} \leq 0.05)$. 
Table 5. Results of sensory analysis: processed pasta versus a commercial one

\begin{tabular}{|l|l|l|l|l|l|}
\hline Pasta & Firmness & Elasticity & Color & Flavor & Overall Acceptability \\
\hline $10 \%$ cassava bagasse and 0.5\% CMC & $6.02 \mathrm{a}$ & $5,78 \mathrm{~b}$ & $5.58 \mathrm{a}$ & $5,26 \mathrm{~b}$ & $5,40 \mathrm{~b}$ \\
\hline Commercial & $6,30 \mathrm{a}$ & $6.28 \mathrm{a}$ & $6.18 \mathrm{a}$ & $5.98 \mathrm{a}$ & $6.22 \mathrm{a}$ \\
\hline
\end{tabular}

Means with different letters in columns indicate significant differences $(p \leq 0.05)$.

a greater acceptance. Similar results were found in pastas with addition of locust fiber ${ }^{34}$, saffron powder ${ }^{35}$ and legume flour ${ }^{36}$, observing a decrease in general acceptability when increasing the quantity of new raw materials used.

\section{Physicochemical Characterization of the Best Pasta}

Physicochemical characterization of the best pasta made ( $10 \%$ cassava bagasse and $0.5 \% \mathrm{CMC})$ is shown in Table 6. There was an increase in fiber content of this pasta with respect to pasta made only of wheat semolina $(0.42 \%)$, thanks to the addition of cassava bagasse which has a higher fiber content than semolina. A similar behavior was observed in pastas added with quinoa flour ${ }^{37}$ and wheat bran, where fiber values between 4.9 and $13.9 \%$ were observed, showing this raw material as a great source of fiber ${ }^{38}$. Likewise ${ }^{13}$ found an increase in protein and fiber content in pasta, thanks to the incorporation of legume flour, specifically from $77 \%$ to $275 \%$ in fiber, compared to pasta made of wheat only $(0.92 \%$ of total fiber).

Differences in the composition of flours used to make pasta are also reflected in the nutritional profile of the final product. This was evidenced when comparing whole pasta with pasta added with flour rich in aleurone, where it was observed that processed pasta had twice the protein

Table 6. Physicochemical characteristics of pasta

\begin{tabular}{|l|l|}
\hline Component & Quantity \\
\hline Moisture & $12.02 \%$ \\
\hline Ashes & $1.74 \%$ \\
\hline Fat & $0.13 \%$ \\
\hline Protein & $6.20 \%$ \\
\hline Carbohydrates & $79.91 \%$ \\
\hline Total Fiber & $13.89 \%$ \\
\hline Soluble Fiber & $2.37 \%$ \\
\hline Insoluble Fiber & $11.52 \%$ \\
\hline
\end{tabular}

content and dietary fiber and less carbohydrate content than whole pasta ${ }^{39}$.

Pasta added with cassava bagasse and CMC can be considered as a "fiber source" food, according to the European Commission's 2006 food standards. However, the nutritional profile of pasta could be improved with the addition of other ingredients such as egg, oil and dehydrated vegetables.

\section{Conclusion}

All pasta dough made with cassava bagasse and CMC showed a behavior similar to an elastic gel, evidencing a storage modulus greater than loss modulus, with a slight dependence on frequency and $\operatorname{Tan}(\delta)$ values less than 1 . An increase in both moduli was found when increasing the amount of cassava bagasse in dough formulation, and thanks to the addition of CMC, the elastic behavior of dough was favored.

Sensory evaluation showed that tasters preferred pasta made with $10 \%$ cassava bagasse and $0.5 \%$ CMC with respect to the others. Highlighting firmness, elasticity, taste, and overall acceptability attributes. When comparing this pasta with a commercial one it was evident that the commercial one obtained better results, except for firmness and color where no statistical difference was evidenced.

The addition of cassava bagasse to pasta formulation improved its fiber content.

\section{Acknowledgment}

To the Government of Sucre and to COLCIENCIAS for their financial support for carrying this study out. To PADES research group of the University of Sucre.

\section{References}

1. DANE. Boletin mensual: Insumos y factores asociados a la produccion agropecuaria. El cultivo de la yuca (Manihotsculenta Crantz). 2016. 
2. Fiorda F, Soares M, Da Silva F, De Moura C, Grosmann M. Physical quality of snacks and technological properties of pre-gelatinized flours formulated with cassava starch and dehydrated cassava bagasse as a function of extrusion variables. LWT - Food Science Technology. 2015; 62(2):1112-9. https://doi.org/10.1016/j.lwt.2015.02.030

3. Alarcon F, Dufour D. Almidon agrio de yuca en Colombia. Tomo I: Produccion y recomendaciones. Cali, Colombia. 1998; p. 1-22.

4. Farias F, Jasko A, Colman T, Pinheiro L, Schnitzler E, Barana A and Demiate I. Characterisation of Cassava Bagasse and Composites Prepared by Blending with LowDensity Polyethylene. Brazilian Archives of Biology and Technology. 2014; 57(6):821-30. https://doi.org/10.1590/ S1516-8913201402506

5. Pandey A, Soccol C, Nigam P, Soccol V, Vandenberghe L, Mohan R. Biotechnological potential of agroindustrial residues. II: cassava bagasse. Bio resource Technology. 2000; 74(1):81-7. https://doi.org/10.1016/ S0960-8524(99)00142-X https://doi.org/10.1016/S09608524(99)00143-1

6. Petitot M, Abecassis J, Micard V. A Review: Structuring of pasta components during processing: impact on starch and protein digestibility and allergenicity. Trends in Food Science Technology. 2009; 20(11):521-32. https://doi. org/10.1016/j.tifs.2009.06.005

7. Aravind N, Sissons M, Fellows M. Effect of soluble fibre (guar gum and carboxymethylcellulose) addition on technological, sensory and structural properties of durum wheat spaghetti. Food Chemistry. 2012; 131:893-900. https://doi. org/10.1016/j.foodchem.2011.09.073

8. Sozer N. Rheological properties of rice pasta dough supplemented with proteins and gums. Food Hydrocolloids. 2009; 23:849-55. https://doi.org/10.1016/j.foodhyd.2008.03.016

9. Li J, Nie S. The functional and nutritional aspects of hydrocolloids in foods. Food Hydrocolloids. 2016; 53:46-61. https://doi.org/10.1016/j.foodhyd.2015.01.035

10. Gallagher E, Gormley T, Arendt E. Recent advances in the formulation of gluten-free cereal-based products. Trends in Food Science \& Technology. 2004; 15(3):143-52. https:// doi.org/10.1016/j.tifs.2003.09.012

11. Larrosa V. Efectos de los hidrocoloides en las caracteristicas fisicoquimicas y reologicas de pastas libres de gluten aptas para individuos celiacos. Disertacion doctoral, Facultad de ciencias exactas. Universidad Nacional de la plata. Buenos Aires. 2014.

12. Silva E, Birkenhake M, Scholten E, Sagi L, Van der Linden E. Controlling rheology and structure of sweet potato starch noodles with high broccoli powder content by hydrocolloids. Food Hydrocolloids. 2013; 30(1):42-52. https://doi. org/10.1016/j.foodhyd.2012.05.002
13. Wojtowicz A and Moscicki L. Influence of legume type and addition level on quality characteristics, texture and microstructure of enriched precooked pasta. LWT - Food Science Technology. 2014; 59:1175-85. https://doi.org/10.1016/j. lwt.2014.06.010

14. AOAC International. Official Methods of Analysis of AOAC International. Ed. 19. Editorial Gaithersburg, MD, USA. Official Method. 2012.

15. Larrosa V, Lorenzo G, Zaritzky N, Califano A. Dynamic rheological analysis of gluten-free pasta as affected by composition and cooking time. Journal of Food Engineering. 2015; 160:11-8. https://doi.org/10.1016/j. jfoodeng.2015.03.019

16. Graca C, Fradinho P, Sousa I, Raymundo A. Impact of Chlorella vulgaris on the rheology of wheat flour dough and bread texture. LWT - Food Science Technology. 2018; 89:466-74. https://doi.org/10.1016/j.lwt.2017.11.024

17. Struck S, Straube D, Zahn S, Rohm H. Interaction of wheat macromolecules and berry pomace in model dough: Rheology and microstructure. Journal of Food Engineering. 2018; 223:109-15. https://doi.org/10.1016/j. jfoodeng.2017.12.011

18. Acosta A, Hernandez EJ, Alvis A. Study of Rheological Properties of Doughs for Pasta with Cassava Bran Addition and Supplemented with Hydrocolloid. Indian Journal of Science and Technology. 2018; 11(31):1-11. https://doi. org/10.17485/ijst/2018/v11i31/130996

19. Cai J, Chiang J, Tan M, Saw L, Xu, Y, Ngan-Loong M. Physicochemical properties of hydrothermally treated glutinous rice flour and xanthan gum mixture and its application in gluten-free noodles. Journal of Food Engineering. 2016; 186:1-9. https://doi.org/10.1016/j.jfoodeng.2016.03.033

20. Mis A, Grundas S, Dziki D, Laskowski J. Use of farinograph measurements for predicting extensor graph traits of bread dough enriched with carob fibre and oat whole meal. Journal of Food Engineering. 2012; 108(1):1-12. https://doi. org/10.1016/j.jfoodeng.2011.08.007

21. Lazaridou A, Duta D, Papageorgiou M, Belc N, Biliaderis C. Effects of hydrocolloids on dough rheology and bread quality parameters in gluten-free formulations. Journal of Food Engineering. 2007; 79(3):1033-47. https://doi. org/10.1016/j.jfoodeng.2006.03.032

22. Barcenas M, De la O-Keller J, Rosell C. Influence of different hydrocolloids on major wheat dough components (gluten and starch). Journal of Food Engineering. 2009; 94(3):241-7. https://doi.org/10.1016/j.jfoodeng.2009.03.012

23. Pejcz E, Spychaj R, Wojciechowicz-Budzisz A, Gil Z. The effect of Plantago seeds and husk on wheat dough and bread functional properties. LWT - Food Science and Technology. 2018; 96:371-7. https://doi.org/10.1016/j.lwt.2018.05.060 
24. Larrosa V, Lorenz G, Zaritzky N, Califano A. Optimization of rheological properties of gluten-free pasta dough using mixture design. Journal of Cereal Science. 2013; 57(3):520-6. https://doi.org/10.1016/j.jcs.2013.03.003

25. Ronda F, Perez S, Angioloni A, Collar C. Impact of viscous dietary fibres on the viscoelastic behaviour of gluten-free formulated rice doughs: a fundamental and empirical rheological approach. Food Hydrocolloids. 2013; 32(2):252-62. https://doi.org/10.1016/j.foodhyd.2013.01.014

26. Olivera DF, Salvadori VO. Effect of freezing rate in textural and rheological characteristics of frozen cooked organic pasta. Journal of Food Engineering. 2009; 90(2):271-6. https://doi.org/10.1016/j.jfoodeng.2008.06.041

27. Foschia M, Peressini D, Sensidoni A, Brennan A, Brennan C. How combinations of dietary fibres can affect physicochemical characteristics of pasta. LWT - Food Science Technology. 2015; 61(1):41-6. https://doi.org/10.1016/j.lwt.2014.11.010

28. Singh S, Singh N. Relationship of polymeric proteins and empirical dough rheology with dynamic rheology of dough and gluten from different wheat varieties. Food Hydrocolloids. 2013; 33(2):342-8. https://doi.org/10.1016/j. foodhyd.2013.04.007

29. Rubel I, Perez E, Manrique G, Genovese D. Fibre enrichment of wheat bread with Jerusalem artichoke inulin: Effect on dough rheology and bread quality. Food Structure. 2015; 3:21-9. https://doi.org/10.1016/j.foostr.2014.11.001

30. Moreira R, Chenlo F, Torres M. Rheology of commercial chestnut flour doughs incorporated with gelling agents. Food Hydrocolloids. 2011; 25(5):1361-71. https://doi. org/10.1016/j.foodhyd.2010.12.015

31. Mora A. Evaluacion de la calidad de coccion y calidad sensorial de pasta a partir de mezclas de semolas de trigo y harina de quinua. Maestria en ciencia y tecnologia de alimentos. Universidad Nacional de Colombia. Medellin. 2012.

32. La Gatta B, Rutigliano M, Padalino L, Conte A, Del Nobile MA, Di Luccia A. The role of hydration on the cooking quality of bran-enriched pasta. LWT-Food Science Technology. 2017; 84:489-96. https://doi.org/10.1016/j.lwt.2017.06.013
33. Pasqualone A, Gambacorta G, Summo C, Caponio F, Di Miceli G, Flagella Z, Maresse P, Piro G, Perrotta C, De Bellis L, Lenucci MS. Functional, textural and sensory properties of dry pasta supplemented with lyophilized tomato matrix or with durum wheat bran extracts produced by supercritical carbon dioxide or ultrasound. Food Chemistry. 2016; 213:545-53. https://doi.org/10.1016/j. foodchem.2016.07.006 PMid:27451216

34. Biernacka B, Dziki D, Gawlik-Dziki U, Rozylo R, Siastala M. Physical, sensorial, and antioxidant properties of common wheat pasta enriched with carob fiber. LWT-Food Science Technology. 2017; 77:186-92. https://doi.org/10.1016/j. lwt.2016.11.042

35. Armellini R, Peinado I, Pittia P, Scampicchio M, Heredia A, Andres A. Effect of saffron (Crocus sativus L.) enrichment on antioxidant and sensorial properties of wheat flour pasta. Food Chemistry. 2018; 254:55-63. https://doi. org/10.1016/j.foodchem.2018.01.174 PMid:29548471

36. Bouasla A, Wojtowicz A, Zidoune, MN. Gluten-free precooked rice pasta enriched with legumes flours: Physical properties, texture, sensory attributes and microstructure. LWT-Food Science and Technology. 2017; 75:569-77. https://doi.org/10.1016/j.lwt.2016.10.005

37. Lorusso A, Verni M, Montemurro M, Coda R, Gobbetti M, Rizzello CG. Use of fermented quinoa flour for pasta making and evaluation of the technological and nutritional features. LWT-Food Science and Technology. 2017; 78:215-21. https://doi.org/10.1016/j.lwt.2016.12.046

38. Vignola MB, Bustos MC, Perez GT. Comparison of quality attributes of refined and whole wheat extruded pasta. LWTFood Science and Technology. 2018; 89:329-35. https://doi. org/10.1016/j.lwt.2017.10.062

39. Bagdi A, Szabo F, Gere A, Kokai Z, Sipos L, Tomoskozi S. Effect of aleurone-rich flour on composition, cooking, textural, and sensory properties of pasta. LWT-Food Science and Technology. 2014; 59(2):996-1002. https://doi. org/10.1016/j.lwt.2014.07.001 